\title{
Evaluación de tres técnicas de irrigación de conducto radicular frente a la actividad del enterococcusfaecalis.
}

\author{
Evaluation of three techniques of root canal irrigation activity against enterococcusfaecalis.
}

Elizabeth Gaspar-Zevallos ${ }^{1, a}$, Zulema Velásquez-Huamán ${ }^{1, b}$, Alexis Evangelista-Alva ${ }^{1, c}$

\section{RESUMEN}

Objetivo: El objetivo de este estudio "in vitro" es comparar la eficacia antibacteriana de tres técnicas de irrigación del conducto radicular: presión positiva, presión negativa y sónica frente a una cepa de enterococcusfaecalisatcc 2012. Materiales y Métodos: Raíces de premolares extraídos calibrados a $16 \mathrm{~mm}$ de longitud apico coronal fueron contaminados con Enterococcusfaecalis ATCC 29212 por 21 días y luego distribuidos aleateoriamente en 3 grupos experimentales con 24 especimenes cada uno: grupo 1, presion positiva con agujas $27 \mathrm{G}$ insertadas a $4 \mathrm{~mm}$ de la longitud de trabajo; grupo 2. Fue irrigado activando las puntas endosónicas a 3mm; grupo3, con el sistema EndoVac. El volumen de irrigantes utilizado para todos los grupos fue de $13 \mathrm{ml}$. El grupo de control negativo fue irrigado con solución salina (volumen total: $13 \mathrm{ml}$ ). Se tomaron muestras después de la irrigación para cultivarlas, a las 24 horas se contabilizaron las unidades formadoras de colonias (UFC's). Resultados: Los tres grupos experimentales fueron más efectivos que el grupo de control negativo en la disminución de la cantidad de bacterias. Conclusiones: No se encontró diferencia estadísticamente significativa entre los tres grupos evaluados.

Palabras clave: TRATAMIENTO ENDODÓNTICO, ENTEROCOCCUSFAECALIS, IRRIGACIÓN, INFECCIÓN DEL CANAL RADICULAR, HIPOCLORITO DE SODIO.

\footnotetext{
ABSTRACT

Facultad de Estomatología. Universidad Peruana Cayetano Heredia. Lima, Perú.

a Bachiller en Estomatología.

b Docente del Departamento Académico de Clínica del Adulto.

c Docente del Departamento Académico de Odontología Social.
}

Introduction: The different types of bacteria found in the root canal suggest that is necessary to pursue a correct cleaning of it; thus, by means of the irrigation techniques disinfection will improve. The aim of this in vitro study is to compare the antibacterial efficacy of 3 different irrigation techniques. Methods: Roots of premolars extracted teeth calibrated to $16 \mathrm{~mm}$ in apex-coronal direction were contaminated with Enterococcus faecalis ATCC 29212 within 21 days and then randomly divided into 3 experimental groups of 24 specimens: group 1, positive pressure irrigation with $27 G$ needles inserted up to 
$4 \mathrm{~mm}$ short of the working length; group 2, same as group 1, but complemented with final irrigant activation by the EndoSonic tips; and group 3, irrigation with the EndoVac system. The irrigants used in all experimental groups were $\mathrm{NaOCl}$ and ethylenediaminetetraacetic acid (EDTA). The diameter preparation was constant for the groups ISO .40/.04 (RaCe). The irrigants volume was $13 \mathrm{~mL}$ for all the groups. The control group was irrigated with saline solution (total volume, $13 \mathrm{~mL}$ ). Samples were taken after irrigation procedures for cultivation and successively colony-forming units (CFUs) were counted after 24 hours. Results: The 3 experimental groups were more effective than the negative control group in reducing bacteria. Conclusions: There was no statistical significant difference between the 3 techniques.

\section{Key words: ENDODONTIC TREATMENT, ENTEROCOCCUS FAECALIS, IRRIGATION, ROOT CANAL INFECTION, SODIUM HYPOCHLORITE.}

\section{INTRODUCCIÓN}

La patología pulpar viene siendo investigada desde hace más de un siglo, con el fin de determinar laetiología, Van Leuwenhoek en 1677 describe la existencia de microorganismos en los "huecos de las raíces" de los dientes, observados a través de su microscopio; iniciando una revolución en el concepto de patología pulpar y dando pase así, a la época de los cultivos y aislamiento de microorganismos, encontrando principalmente los de tipo cocos, bacilos y espirilos $(1,2)$.

Los primeros resultados obtenidos fueron insuficientes debido a que los métodos de obtención y cultivo de las muestras, eran incorrectos. Con el avance de la tecnología y la perfección de las técnicas de cultivo se descubrió los bacilos anaerobios gram negativos y su relación con otros microorganismos lo que generaba las infecciones mixtas (1).

La desinfección eficaz de todo el conducto radicular, será lograda cuidando cada detalle de la preparación biomecánica, proceso durante el cual se elimina toda causa de la infección. La irrigación realizada durante esta fase tiene dos puntos esenciales, primero la técnica y segundo la solución a utilizar. Actualmente la solución por excelencia es el hipoclorito de sodio, su historia data desde la primera guerra mundial cuando Henry Dakin empieza a utilizarla en una concentración de $0.5 \%$ para la desinfección de heridas, y luego fue aceptado para su uso en endodoncia en diferentes concentraciones $(3,4,5)$.

Las técnicas de irrigación se clasifican en dos tipos, las técnicas manuales y las técnicas asistidas por máquinas. En las técnicas manuales se describe a la técnica convencional la cual se fundamenta en el principio de la presión positiva, las desventajas son la imposibilidad de limpiar el tercio apical y la alta probabilidad de extrusión de la solución toxicaque irrita el tejido perirradicular. A pesar de las evidenciados se sigue usando en la práctica clínica (6).

En 1957 se sugiere utilizar el ultrasonido para la instrumentación y limpieza del conducto radicular. Actualmente se utiliza no solo el ultrasonido sino también el sistema sónico para la irrigación radicular los cuales cuentan con diferentes maquinas y de distintas casas dentales, como el EndoActivator $(7,8,9)$.

La Teoría de la Burbuja propuesta por Chow en el año 1983, explica que la presión positiva usada para la irrigación formaba a nivel del tercio apical una gran burbuja de aire semejante a un tampón que impide la correcta desinfección del conducto (6). Entonces desarrollan el principio de la presión negativa, que consiste en que el irrigante es inyectado y succionado del conducto radicular, garantizando así el flujo constante en el tercio apical y la no extrusión de este, comoel EndoVac. $(10,11,12,13,14)$.

El propósito de la investigación fue evaluar "in vitro" la eficacia antibacteriana de tres técnicas de irrigación del conducto radicular: presión positiva, presión negativa y sónica frente a una cepa de Enterococcusfaecalis ATCC 29212.

\section{MATERIALES Y MÉTODOS}

El grupo experimental estuvo conformado por 76 dientes premolares inferiores extraídos, todos con ápices completos, sin tratamiento endodóntico y con leve curvatura determinada según la técnica radiográfica de Scheneider.

Se asignaron de manera aleatoria 24 premolares por cada una de las tres técnicas a evaluar, los 4 restantes 


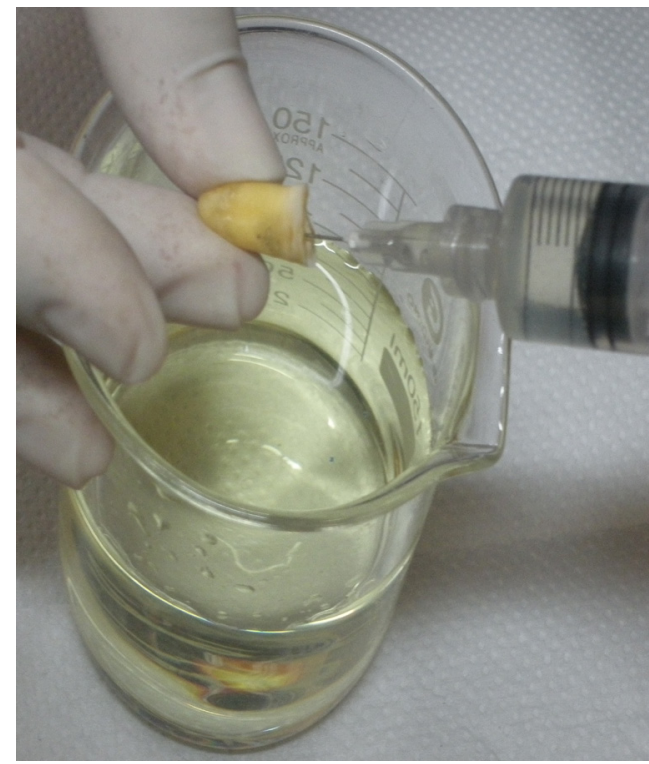

Fig. 1 Irrigación con Técnica de Presión

se utilizaron para el grupo de control negativo. El estudio comprendió las siguientes etapas:

Preparación de los especímenes: Los dientes fueron conservados en solución salina hasta el momento de la preparación. Se realizó la desinfección superficial de las piezas sumergiéndolas en Hipoclorito de Sodio al 5.25\% por 12 horas. Luego se seccionaron las coronas, dejando a $16 \mathrm{~mm}$ de longitud a partir del ápice anatómico, luego se procedió a realizar la apertura cameral, con una fresa de diamante $\mathrm{N}^{\circ} 2$ estéril de alta velocidad (DentsplyMaillefer, Ballaigues, Suiza), bajo refrigeración constante. Para realizar la estandarización de la longitud de trabajo se permeabilizó el canal con lima K ISO 10 (DentsplyMaillefer, Ballaigues, Suiza), se realizó un ajuste incisal en aquellas que excedían los 16 $\mathrm{mm}$. Fig. 1-4. Posteriormente, se instrumentó cada pieza con lima K ISO 15, K ISO 20 y K ISO 25

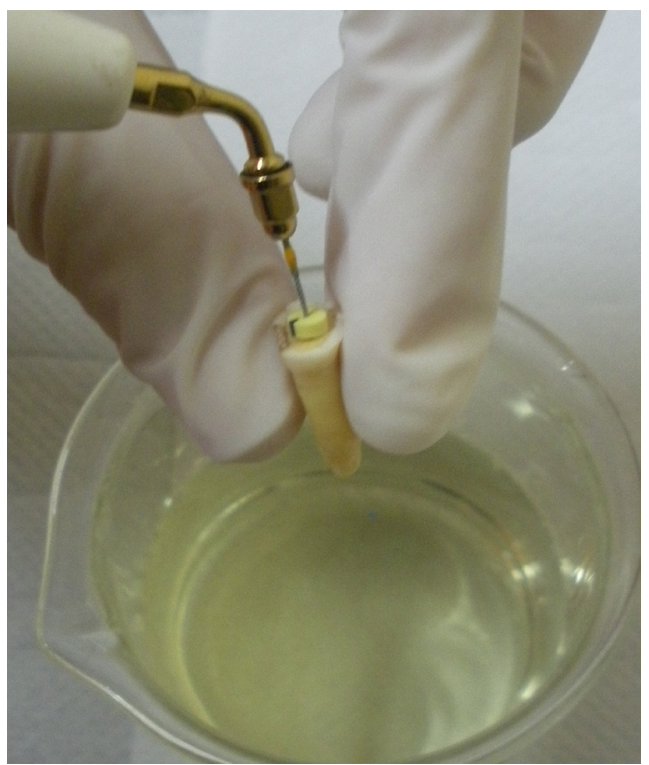

Fig. 2 Irrigación con Técnica Sónica

(DentsplyMaillefer, Ballaigues, Suiza). Se tomaron radiografías para comprobar el grado de curvatura de cada uno de los especímenes con la lima K ISO 25 (DentsplyMaillefer, Ballaigues, Suiza) en el conducto radicular de acuerdo a los criterios de inclusión Fig 5.

La Preparación biomecánicase completó con el sistema rotacional RaCe (FKG Dentaire, La-Chauxde-Fods, Switzerland) siguiendo las indicaciones del fabricante, hasta 40/0.4; para todos los especímenes se utilizó $1 \mathrm{ml}$ de agua destilada, entre lima y lima, como solución irrigante. Fig 6. Luego se realizó un baño de ultrasónico con EDTA al 17\% e hipoclorito de sodio $5.25 \%$ por cuatro minutos respectivamente para remover el barro dentinario.

Esterilización y prueba de esterilidad: Los especímenes fueron esterilizados en autoclave a $121^{\circ} \mathrm{C}$ por 15 minutos. Posteriormente se realizó

Irrigación con Técnica a Presión negativa

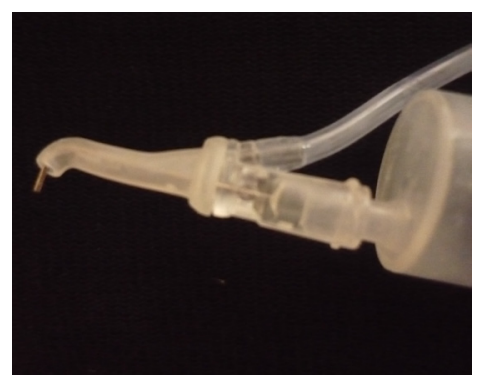

Fig. 3

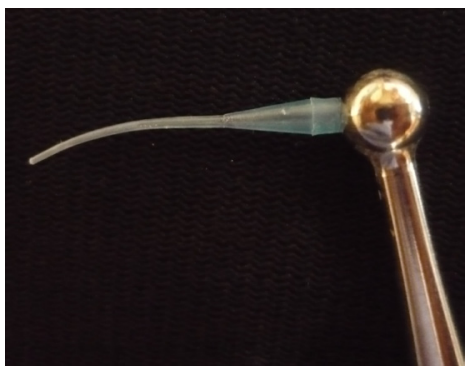

Fig. 4

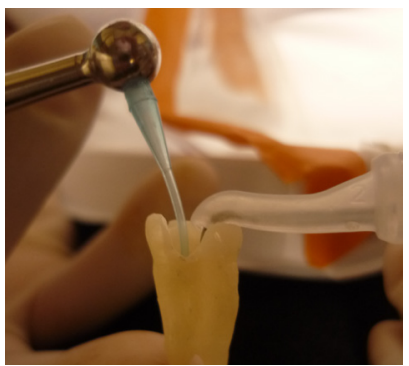

Fig. 5 
la prueba de esterilidad, transfiriéndolos al medio de cultivo BHI (Oxoid, Hamphire, England), e incubándolos por 24 horas a $37^{\circ} \mathrm{C}$. Fig. 7-14.

Activación de la cepa de enterococcusfaecalis ATCC 29212 se realizó llevando con una asada las bacterias a un tubo de caldo de BHI (Oxoid, Hamphire, England), a $37^{\circ} \mathrm{C}$ por 24 horas. Una vez activada a través de la tinción Gram correspondiente, se tomó $1 \mathrm{ul}$, 106célulasaprox. Luegose llevó a otro tubo de caldo BHI (Oxoid, Hamphire, England) para realizar la dilución a 0.5 de Mc Farland. Este paso se realizó visualmente con luz adecuada para comparar el inóculo con el estándar de Mc Farland contra un fondo blanco con líneas negras contrastantes Fig 15-16.

Inoculación del enterococcusfaecalis: Cada especimen se mantuvo en un tubo de ensayo individual con $3 \mathrm{ml}$ de caldo BHI (Oxoid, Hamphire, England) que fue cambiado cada dos días, durante tres semanas. La pureza de los cultivos se comprobó a intervalos cada semana bajo microscopio óptico y tinción de Gram Fig. 17-19.

Protocolo de desinfección de las piezas infectadas: Se llenaron los conductos de los 76 especímenes de solución salina estéril previamente a la desinfección con el sistema de irrigación indicado. Se dividieron aleatoriamente los especímenes en tres grupos postinoculación dejando 4 especímenes para que actúen de control negativo, los cuales fueron irrigados solamente con solución salina durante 90 segundos.

ElGrupo 1. Técnica de presión positiva, se aplicaron secuencialmente $6 \mathrm{ml}$ de $\mathrm{NaOCl} 2.5 \%, 3 \mathrm{ml}$ de EDTA al $17 \%$ y $6 \mathrm{ml}$ de $\mathrm{NaOCl} 2.5 \%$ con aguja $27 \mathrm{G} \mathrm{x} 1 / 2$ “ (NIPRO,Europa) hasta $4 \mathrm{~mm}$ antes de la longitud de trabajo por 30seg con cada solución. Se realizó el movimiento de entrada y salida del conducto durante la administración delasolución sin llegar a retirar la aguja en su totalidad. (ANEXO 7 Fig20-21)

El Grupo 2 de la técnica sónica, se utilizó inicialmente $6 \mathrm{ml}$ de $\mathrm{NaOCl}$ al $2.5 \%$ y $3 \mathrm{ml}$ de EDTA al $17 \%$ con aguja $27 \mathrm{G} \times 1 / 2$ " (NIPRO,Europa), durante 30seg cada uno; finalmente, se realizó la sonicación de $6 \mathrm{ml} \mathrm{NaOCl}$ al 2.5\% manteniéndolo en el canal radicular, con la punta azul \# 30 / 0.2 a $3 \mathrm{~mm}$ de la longitud de trabajo, con $10000 \mathrm{cpm}$ y durante $30 \mathrm{seg}$. (ANEXO 7 Fig. 22-23)

En el Grupo 3 Para la técnica de presión negativa, se utilizó el sistema EndoVac,iniciando con $6 \mathrm{ml}$ de $\mathrm{NaOCl}$ al $2.5 \%$ durante $30 \mathrm{seg}$. con la punta master y luego hasta la longitud de trabajo, con la microcánula donde se completó el ciclo de la siguiente manera: $3 \mathrm{ml}$ de EDTA al $17 \%$ durante 30 segundos y $6 \mathrm{ml}$ de hipoclorito de sodio $2.5 \%$ por 30 segundos. Al final del ciclo se dejó la microcánula a nivel de la longitud de trabajo para remover el exceso de irrigante.

Fig. 24-26.

Tabla $\mathrm{N}^{\circ}$ 1. Promedios de crecimiento bacteriano (CFU), en placas de agar tras lautilización de tres técnicas de irrigación en piezas uniradiculares infectadas con Enterococcus faecalis ATCC 29212 a las 24 y 48 horas.

\begin{tabular}{|c|c|c|c|c|c|c|c|}
\hline $\begin{array}{c}\text { Técnicas de Irrigación } \\
\text { Tiempo } 24 \text { horas }\end{array}$ & $\mathrm{n}$ & Media & Desv. tip & Minímo & Máximo & Normalidad $(+)$ & significativa $(*)$ \\
\hline Presión Positiva & 23 & $6.78 \times 10^{7} \mathrm{UFC}$ & 29.72 & 0.00 & 143.00 & $<0.001$ & \multirow{4}{*}{$<0.001$} \\
\hline Sónico & 21 & $34.23 \times 10^{7} \mathrm{UFC}$ & 96.38 & 0.00 & 416.00 & $<0.001$ & \\
\hline Presión Negativa & 22 & $7.77 \times 10^{7} \mathrm{UFC}$ & 15.76 & 0.00 & 54.00 & $<0.001$ & \\
\hline Control Negativo & 4 & $13455.00 \times 10^{7} \mathrm{UFC}$ & 4543.46 & 9828.00 & 19656.00 & 0.334 & \\
\hline \multicolumn{8}{|l|}{ Tiempo 48 horas } \\
\hline Presión Positiva & 23 & $6.78 \times 10^{7} \mathrm{UFC}$ & 29.72 & 0.00 & 143.00 & $<0.001$ & \multirow{4}{*}{$<0.001$} \\
\hline Sónico & 21 & $34.23 \times 10^{7} \mathrm{UFC}$ & 96.38 & 0.00 & 416.00 & $<0.001$ & \\
\hline Presión Negativa & 22 & $7.77 \times 10^{7} \mathrm{UFC}$ & 15.76 & 0.00 & 54.00 & $<0.001$ & \\
\hline Control Negativo & 4 & $13455.00 \times 10^{7} \mathrm{UFC}$ & 4543.46 & 9828.00 & 19656.00 & 0.334 & \\
\hline
\end{tabular}


Después de la irrigación de las piezas se colocaron 2 conos de papel estériles en el canal radicular por un minuto, luego fueron transferidos a tubos de ensayo con $15 \mathrm{ml}$ de caldo BHI para incubarlos por $24 \mathrm{~h}$ a $37^{\circ} \mathrm{C}$.

Inoculación de las placas: La inoculación de las 76 placas se realizó según las indicaciones del método de vertido en placa con el fin de realizar el recuento de las unidades formadoras de colonias (UFC), al término del periodo de incubación los tubos fueron agitados en el vortex por 1 minuto, se tomaron $20 \mathrm{ul}$, para realizar 6 diluciones seguidas en 180ul de agua peptonada. De la última dilución mediante pipeta estéril se tomó una muestra de $100 \mathrm{uL}$ para colocarla en el centro de las placas Petri, correctamente rotuladas con los datos pertinentes. Seguidamente se agregaron $20 \mathrm{ml}$ de $\mathrm{BHI}$ agar fundido a $45^{\circ} \mathrm{C}$ Fig 27-31. Para homogenizar, se mezcló mediante 6 movimientos de derecha a izquierda, 6 en el sentido de las manecillas del reloj, 6 en sentido contrario y 6 de atrás a adelante, sobre una superficie lisa y horizontal hasta lograr la completa incorporación del inóculo en el medio; se incubaron las placas en posición invertida durante 48 horas a $37^{\circ} \mathrm{C}$ en jarras de anaerobiosis.

Lectura de las placas e interpretación de los resultados: A las 24 y 48 horas siguientes a la incubación, cada placa fue examinada. Se consideraron las unidades formadoras de colonias (UFC) uniformes en una capa homogénea de crecimiento Fig 32-38.

\section{RESULTADOS}

El estudio se basó en la evaluación de la eficacia antibacteriana de tres técnicas de irrigación: presión positiva, sónica y presión negativa en 76 placas de cultivo frente a cepas de Enterococcusfaecalis.

Se contabilizaron las unidades formadoras de colonias (UFC), previo reconocimiento de la cepa en cuestión mediante la tinción Gram.

Se inocularon 24 placas de cultivo por cada una de las técnicas de irrigación y 4 para el control negativo. Se descartaron placas por contaminación en el orden siguiente: grupo 1, una placa, grupo 2,3 placas y del grupo 3, 2 placas.

Con las placas restantes se obtuvieron los promedios de la eficacia antibacteriana, como sigue: para la presión positiva $6.78 \times 107 \mathrm{UFC}$, para la técnica sónica 34.23 x 107UFC, para la presión negativa 7.77 x 107UFC y para el control positivo 13455.00 x 107UFC. Además, según la prueba de Kruskal-Wallis se determina que existe diferencia estadísticamente significativa ( $p$ $<0.001)$ entre las técnicas de irrigación y el control negativo. No se encontró variación en el número de unidades formadoras de colonias al evaluar las placas a las 24 h y 48 h. (Tabla 1 )

Así mismo, utilizando la prueba U de MannWhitney se comparó las técnicas de irrigación y cada una de estas con el control positivo. Llegando a obtener

Tabla $\mathrm{N}^{\circ}$ 2. Comparación estadística de los Promedios de crecimiento bacteriano (CFU), en placas de agar de tres técnicas de irrigación en piezas uniradiculares infectadas con enterococcus faecalis ATCC 29212

\begin{tabular}{ccccc}
\hline Técnicas de Irrigación & Media & Técnicas de Irrigación & Media & significativa $(*)$ \\
\hline Presión Positiva & $6.78 \times 10^{7} \mathrm{UFC}$ & Presión Negativa & $7.77 \times 10^{7} \mathrm{UFC}$ & 0.052 \\
Presión Positiva & $6.78 \times 10^{7} \mathrm{UFC}$ & Sónico & $34.23 \times 10^{7} \mathrm{UFC}$ & 0.459 \\
Presión Negativa & $7.77 \times 10^{7} \mathrm{UFC}$ & Sónico & $34.23 \times 10^{7} \mathrm{UFC}$ & 0.414 \\
Presión Positiva & $6.78 \times 10^{7} \mathrm{UFC}$ & Control Negativo & $13455.00 \times 10^{7} \mathrm{UFC}$ & $<0.001$ \\
Presión Negativa & $7.77 \times 10^{7} \mathrm{UFC}$ & Control Negativo & $13455.00 \times 10^{7} \mathrm{UFC}$ & $<0.001$ \\
Sónico & $34.23 \times 10^{7} \mathrm{UFC}$ & Control Negativo & $13455.00 \times 10^{7} \mathrm{UFC}$ & $<0.001$ \\
\hline
\end{tabular}

(*) Prueba U de Mam Whitney p $>0.05$ 


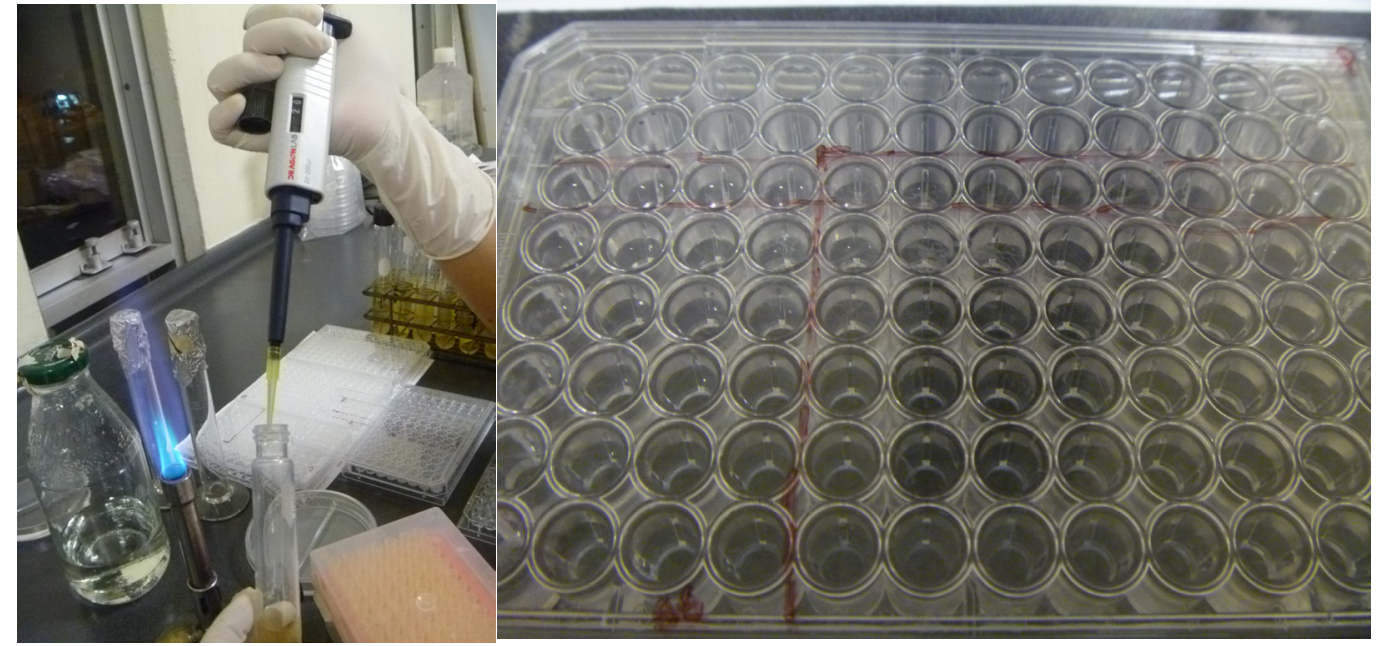

Fig. 6 Inoculación de las placas.

que entre las técnicas aplicadas no existe diferencia estadísticamente significativa. Pero al comparar los resultados obtenidos de cada una de las técnicas con los resultados obtenidos del grupo de control positivo se evidencia diferencia estadísticamente significativa $(\mathrm{p}<0.001)$. (Tabla 2)

\section{DISCUSION}

El propósito de este estudio fue evaluar "in vitro" la eficacia antibacteriana de tres técnicas de irrigación del conducto radicular: presión positiva, presión negativa y sónica en piezas uniradiculares infectadas con Enterococcusfaecalis ATCC 29212.

Según la teoría de Chow postulada en el año 1983 el avance de los líquidos a través de canales estrechos y cerrados atrapa el aire a su paso, por lo tanto lo encapsula a nivel del tercio apical y dificulta que el irrigante cumpla su función a este nivel. El estudio de este fenómeno conocido como la burbuja de aire o "vapor lock" ha dado como resultado el planteamiento de nuevas técnicas de irrigación las que buscan superar esta barrera para el éxito del tratamiento endodóntico $(6,7,16,17,28)$.

Para la técnica de presión positiva se utilizaron agujas $27 \mathrm{G}$, un tiempo de 30 segundos por solución y un volumen determinado, para estandarizar la presión ejercida durante el procedimiento. En el estudio realizado por Boutsioukis y Col. se demostró que la aguja debe localizarse como mínimo a $3 \mathrm{~mm}$ y como máximo a $6 \mathrm{~mm}$ de la longitud de trabajo para garantizar que la solución llegue hasta el tercio apical $(7,10,21,22,23)$.
Los resultados obtenidos con el sistema sónico el cual presenta un nodo y un antinodo dispuestos en ambos extremos de la lima, para evitar el desgaste de las paredes laterales durante una sonicación pasiva. Como se demostró en el estudio de Jiang y Col. (21). La onda oscilante longitudinal que se genera se expande de manera continua a lo largo del canal radicular garantizando la desinfección del conducto incluso con una mínima sonicación de 20 segundos. Brito y col.28 activan el irrigante por $30 \mathrm{seg}$ a $3 \mathrm{~mm}$ de la longitud de trabajo con la punta azul según el protocolo sugerido por Ruddle, obteniendo resultados positivos referentes a la desinfección.

En este estudio se realizó la sonicación por 30 segundos los cuales no son perjudiciales para la pared radicular interna. Contribuyendo de está manera con la estandarización de tiempo total de irrigación. El

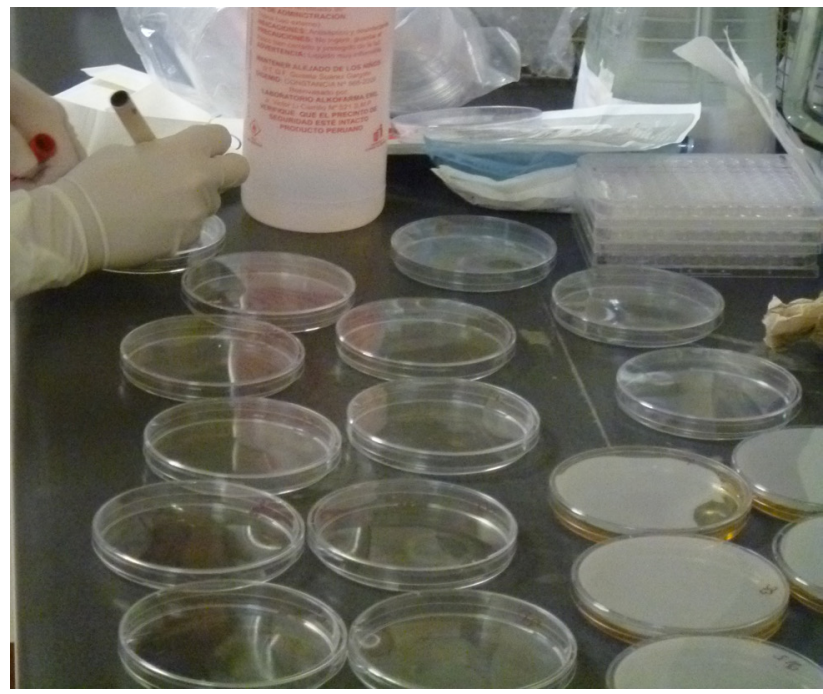

Fig. 7 
sistema sónico sugiere que al ser menor la frecuencia de oscilación el tiempo de activación debería ser mayor; lo cual explica la presencia de placas con números de unidades formadoras de colonias altos en el caso de esta técnica de irrigación.7, 20,21, 23, 24, 27,28

La técnica de presión negativa se llevó a cabo con el EndoVac, los resultados obtenidos sugieren que es un sistema eficaz. Sin embargo requiere una preparación mínima con un instrumento calibre 35 a nivel apical por lo que no es aplicable en la primera etapa de la preparación biomecánica. El protocolo del fabricante refiere que el volumen de solución debe ser mayor a los demás sistemas lo cual sería favorable para la desinfección $(7,11,12,13,14,25)$.

El estudio se realizó "in vitro" como la mayoría de estudios que implican la comparación de los distintos sistemas. Se escogió como especie bacteriana al Enterococcusfaecalis, la cual según Gomes y Col. (19), está directamente relacionada con las infecciones recurrentes por ser un anaerobio facultativo grampositivo que presenta una membrana rica en peptidoglucanos, por esto ante la limpieza deficiente es capaz de reactivar la infección $(10,15,25,26,27)$.

Siendo la irrigación parte importante de la preparación biomecánica, Baker y Col (16), mencionan que una generosa cantidad de solución es importante para el éxito del tratamiento. Lisha y col. (28) sugieren el uso dual de esta mejora los resultados. El estudio se realizó con hipoclorito de sodio $(\mathrm{NaOCl})$ y el ácido etilendiaminotetracético (EDTA). El primero, disuelve el debris orgánico, elimina bacterias y sus productos; el segundo es un quelante que remueve los restos inorgánicos $(7,18,19,28)$.

Se utilizó el protocolo aprobado por el NationalCommitteeforClinicalLaboratoryStandards (NCCLS) para efectuar las pruebas de sensibilidad antimicrobianas. Técnica que permite realizar un conteo individualizado en cada grupo $(7,15,28)$.

Si bien en los resultados obtenidos no existe diferencia significativa entre las técnicas aplicadas, la tendencia en el número de UFC en la mayoría de placas observadas es hacia cero; los cuales indican que las técnicas son eficaces frente al Enteroccocusfaecalis.
La presencia de placas con un alto número de UFC podría estar asociado a la variación en el grado de curvatura de los especímenes los cuales fueron seleccionados entre $0^{\circ}$ y $20^{\circ}$.

El estudio sugiere que el movimiento delasolución genera un flujo constante, como las técnicas asistidas por máquinas, y no como en la técnica de presión positiva. Este flujo generado es importante en la limpieza a lo largo del canal radicular, para garantizar el éxito del tratamiento endodóntico $(11,16,17,28)$.

\section{CORRESPONDENCIA}

Elizabeth Gaspar Zevallos

Calle Manuel Bañon No 395

San Isidro, Lima, Perú

Correo electrónico:

elizabethgasparzevallos@hotmail.com

\section{REFERENCIAS BIBLIOGRÁFICAS}

1. Weine F, Pisano J. Microbiología endodóncica. En: Weine F, editor. Tratamiento endodóncico. Madrid: HardcourtBrace; 1997. p. 694-713.

2. Goldstein J. Microbiología de la endodoncia. En: Ingle J, Taintor J, editores. Endodoncia. México: Interamericana; 1988. p. 576-84.

3. Pejoan J, editor. Historia de la Endodoncia. [Internet]. España: Comunidad de endodoncia; 2008 [citado 20 Enero 2008]. Disponible en: http://www.endoroot.com/ modules/news/pdf/pdf.php?storyid $=76$.

4. Leonardo M. Endodoncia. Buenos Aires: Ed. Panamericana; 2009. p. 31-42.

5. Ingle $\mathrm{J}$, Beveridge $\mathrm{E}$, Glick $\mathrm{D}$ y col. Terapéutica endodóntica moderna. En: Ingle J, Taintor J, editores. Endodoncia. México: Interamericana; 1988. p. 1- 55.

6. Chow TW. Mechanical effectiveness of root canal irrigation.J Endod. 1983;9(11):475-9.

7. Gu LS, Kim JR, Ling J, Choi KK, Pashley DH, Tay FR. Review of contemporary irrigant agitation techniques and devices. J Endod. 2009;35(6):791-804.

8. Pejoan J, editor. Novedades Endodoncia. [Internet]. España: Comunidad de endodoncia; 2008 [citado 13 setiembre 2007]. Disponible en: http://www.endoroot. $\mathrm{com} /$ modules $/$ news $/$ pdf $/$ pdf.php?storyid $=59$

9. Pejoan J, editor. Irrigación y desinfección en Endodoncia. [Internet]. España: Comunidad de endodoncia; 2008 [citado 9 enero 2008]. Disponible en: http://www. endoroot.com $/$ modules $/$ news $/$ pdf/pdf.php?storyid=73

10.Hockett JL, Dommish JK, Johnson JD, Cohenca N. Antimicrobial efficacy of two irrigation techniques in tapered and nontapered canal preparations: An in vitro 
study. J Endod. 2008 Nov;34(11):1374-7

11.Schoeffel GJ. The EndoVac method of endodontic irrigation: safety first. Dent Today. 2007;26(10):92-6.

12.SchoeffelGJ.TheEndoVac method of endodontic irrigation, Part 2: Efficacy. Dent Today. 2008;27(1):867.

13.Schoeffel GJ. The EndoVac method of endodontic irrigation, Part 3: System components and their interaction. Dent Today. 2008;27(8):106-11.

14.Schoeffel GJ. The EndoVac method of endodontic irrigation, Part 4: Clinical use. DentToday. 2009;28(6):66-7.

15.Gomes B, Pinheiro E, Gadê-Neto C, Sousa E, Ferraz C, Zaia A, et al. Microbiological examination of infected dental root canals.Oral Microbiol Immunol. 2004;19:71-6.

16.Baker NA, Eleazer PD, Averbach RE, Seltzer S. Scanning electron microscopic study of the efficacy of various irrigating solutions. J Endod. 1975;1(4):127-35.

17.Trepagnier CM, Madden RM, Lazzari EP. Quantitative study of sodium hypochlorite as an in vitro endodontic irrigant. J Endod 1977;3(5):194-6.

18.Pasqualini D, CuffiniAM, Scotti N, Mandras N, Scalas D, Pera F, Berutti E. Comparative evaluation of the antimicrobial efficacy of a 5\% sodium hypochlorite subsonic-activated solution. J Endod. 2010;36(8):1358-60.

19.Grande NM, Plotino G, Falanga A, Pomponi M, Somma F. Interaction between EDTA and sodium hypochlorite: a nuclear magnetic resonance analysis. J Endod. 2006;32(5):460-4.

20.Lea SC, Walmsley AD, Lumley PJ. Analyzing endosonic root canal file oscillations: an in vitro evaluation.J Endod. 2010;36(5):880-3.
21.Jiang LM, Verhaagen B, Versluis M, van der Sluis LW. Evaluation of a sonic device designed to activate irrigant in the root canal. J Endod. 2010;36(1):143-6.

22.Fukumoto Y, Kikuchi I, Yoshioka T, Kobayashi C, Suda H. An ex vivo evaluation of a new root canal irrigation technique with intracanal aspiration.IntEndod J 2006;39(2):93-9.

23.Tsurumachi T, Takita T, Hashimoto K, Katoh T, Ogiso B. Ultrasonic irrigation of a maxillary lateral incisor with perforation of the apical third of the root. J Oral Sci. 2010;52(4):659-63.

24.Uroz-Torres D, González-Rodríguez MP, FerrerLuqueCM.Effectiveness of the EndoActivator System in removing the smear layer after root canal instrumentation. J Endod. 2010;36(2):308-11.

25.Da Silva LA, Nelson-Filho P, da Silva RA, Flores DS, Heilborn C, Johnson JD, Cohenca N. Revascularization and periapical repair after endodontic treatment using apical negative pressure irrigation versus conventional irrigation plus triantibioticintracanal dressing in dogs' teeth with apical periodontitis. Oral Surg Oral Med Oral Pathol Oral RadiolEndod. 2010;109(5):779-87.

26.Nielsen BA, Craig Baumgartner J. Comparison of the EndoVac system to needle irrigation of root canals. J Endod. 2007;33(5):611-5.

27.Desai P, Himel V. Comparative safety of various intracanal irrigation systems. J Endod2009; 35(4):5459.

28. Brito PR, Souza LC, Machado de Oliveira JC, Alves FR, De-Deus G, Lopes HP, Siqueira JF Jr. Comparison of the effectiveness of three irrigation techniques in reducing intracanal Enterococcus faecalis populations: an in vitro study. J Endod. 2009;35(10):1422-7.

Recibido : 13-01-2012

Aceptado: 02-04-2012 